\title{
Expression of DNA ligase IV is linked to poor prognosis and characterizes a subset of prostate cancers harboring TMPRSS2:ERG fusion and PTEN deletion
}

\author{
KATHARINA GRUPP ${ }^{1,2^{*}}$, LAURA ROETTGER ${ }^{1 *}$, MARTINA KLUTH $^{1}$, CLAUDIA HUBE-MAGG $^{1}$, \\ RONALD SIMON $^{1}$, PATRICK LEBOK ${ }^{1}$, SARAH MINNER ${ }^{1}$, MARIA CHRISTINA TSOURLAKIS ${ }^{1}$, \\ CHRISTINA KOOP ${ }^{1}$, MARKUS GRAEFEN $^{3}$, MEIKE ADAM $^{3}$, ALEXANDER HAESE $^{3}$, CORINNA WITTMER $^{1}$, \\ GUIDO SAUTER $^{1}$, WALDEMAR WILCZAK ${ }^{1}$, HARTWIG HULAND ${ }^{3}$, THORSTEN SCHLOMM ${ }^{3,4}$, \\ STEFAN STEURER $^{1}$ and TILL KRECH ${ }^{1}$ \\ ${ }^{1}$ Institute of Pathology; ${ }^{2}$ Department of General, Visceral and Thoracic Surgery and Clinic; ${ }^{3}$ Martini-Clinic, \\ Prostate Cancer Center; ${ }^{4}$ Department of Urology, Section for Translational Prostate Cancer Research, \\ University Medical Center Hamburg-Eppendorf, D-20246 Hamburg, Germany
}

Received April 7, 2015; Accepted May 18, 2015

DOI: $10.3892 / o r .2015 .4080$

\begin{abstract}
DNA ligases are essential for the maintenance of genome integrity as they are indispensable for DNA replication, recombination and repair. The present study was undertaken to gain insights into the prevalence and clinical significance of ligase IV (LIG4) expression in prostate cancer. A total of 11,152 prostate cancer specimens were analyzed by immunohistochemistry for LIG4 expression. Results were compared to follow-up data, ERG status and deletions at PTEN, 3p13, 5q21 and $6 \mathrm{q} 15$. LIG4 expression was predominantly localized in the nucleus of the cells with increased intensities in malignant as compared to benign prostate epithelium. In prostate cancer, LIG4 expression was found in $91 \%$ of interpretable tumors, including $12 \%$ cancers with weak, $23 \%$ with moderate and $56 \%$ with strong LIG4 positivity. Strong LIG4 expression was tightly linked to advanced Gleason score $(\mathrm{P}<0.0001)$ and positive nodal involvement $(\mathrm{P}=0.03)$. There was a remarkable accumulation of strong LIG4 expression in tumors harboring TMPRSS2:ERG fusion and PTEN deletions $(\mathrm{P}<0.0001$ each). High LIG4 expression was also tightly related to early biochemical recurrence when all tumors $(\mathrm{P}<0.0001)$ or the subsets of ERG-negative $(\mathrm{P}=0.0004)$ or ERG-positive pros-
\end{abstract}

Correspondence to: Dr Ronald Simon, Institute of Pathology, University Medical Center Hamburg-Eppendorf, Martinistr 52, D-20246 Hamburg, Germany

E-mail: r.simon@uke.de

*Contributed equally

Abbreviations: DSB, double-strand breaks; HR, homologous recombinations; NHEJ, non-homologous DNA end-joining

Key words: LIG4, PTEN, ERG, prostate cancer, tissue microarray tate cancers $(\mathrm{P}=0.006)$ were analyzed. Multivariate analysis including parameters that are available before surgery demonstrated independent association with biochemical recurrence for advanced Gleason grade on biopsy, high preoperative PSA level, high clinical stage ( $\mathrm{P}<0.0001$ each) and for LIG4 immunostaining $(\mathrm{P}=0.03)$. Our study identifies LIG4 as a predictor of an increased risk for early PSA recurrence in prostate cancer. Moreover, the strong association with TMPRSS2:ERG fusion and PTEN deletions suggest important interactions between these pathways in prostate cancers.

\section{Introduction}

Prostate cancer represents a major cause of cancer-related mortality and morbidity (1). The majority of prostate cancers behave in an indolent manner, but a subset is highly aggressive. Despite recent advances in research, the only established pretreatment prognostic parameters currently include Gleason grade and tumor extent on biopsies, preoperative PSA and clinical stage. As these data are statistically powerful but not sufficient for optimal individual treatment decisions, it can be hoped, that a better understanding of the biology of the disease will eventually lead to better prognostic biomarkers.

DNA double-strand breaks (DSBs) are highly cytotoxic lesions that typically occur during cell division but can also be induced by exogenous noxes including ionizing radiation and various DNA-damaging chemicals (2). Cells typically repair DSBs by homologous recombination (HR) or non-homologous DNA end-joining (NHEJ) pathways (3). NHEJ deficiencies and unrepaired DSBs can result in severe cellular consequences ranging from death to neoplastic transformation (3-9).

DNA ligase IV (LIG4) plays an essential role in the NHEJ machinery, the major DSB repair mechanism $(10,11)$. Hypomorphic LIG4 mutations lead to LIG4 syndrome characterized by immunodeficiency, microcephaly, growth retardation, unusual facial features, developmental delay and acute radiosensitivity, genomic instability and malignancy (12). 
Moreover, polymorphic variants (SNP) in LIG4 has been identified in several malignancies (13-17) including prostate cancers $(18,19)$.

In a recent study we identified LIG4 as a potentially relevant gene in prostate cancer, which can be inactivated by mutation and genomic deletion $(20,21)$. The present study was undertaken to further investigate LIG4 protein expression in prostate cancer and its association with tumor phenotype, outcome and key genomic alterations. For this purpose a tissue microarray containing 11,152 prostate cancer specimens with follow-up information and attached molecular information was utilized. Our data identify a tight link of increased LIG4 expression to tumor phenotype, early PSA recurrence, ERG fusion and PTEN deletions in prostate cancer.

\section{Materials and methods}

Patients. Radical prostatectomy specimens were available from 11,152 patients, undergoing surgery between 1992 and 2011 at the Department of Urology, and the Martini Clinics at the University Medical Center Hamburg-Eppendorf. Follow-up data were available for a total of 9,695 patients with a median follow-up of 36.8 months (range, 1-228 months, Table I). Prostate-specific antigen values were measured following surgery and recurrence was defined as a postoperative PSA of $0.2 \mathrm{ng} / \mathrm{ml}$ and increasing at first of appearance. All prostate specimens were analyzed according to a standard procedure, including a complete embedding of the entire prostate for histological analysis (22). The TMA manufacturing process was described previously in detail (23). In short, one 0.6-mm core was taken from a representative tumor area from each patient. The tissues were distributed among 24 TMA blocks, each containing 144-522 tumor samples. Presence or absence of cancer tissue was validated by immunohistochemical AMACR and 34BE12 analysis on adjacent TMA sections. For internal controls, each TMA block also contained various control tissues, including normal prostate tissue. The molecular database attached to this TMA contained results on ERG expression in 9,628, ERG break apart by fluorescence in situ hybridization (FISH) analysis in 6,106 [expanded from (24)], and deletion status of 5q21 in 3,037 [expanded from (25)], $6 q 15$ in 3,528 [expanded from (26)], PTEN in 6,130 [expanded from (27)], and 3p13 in 1,290 [expanded from (28)] tumors. Analysis of patient and corresponding histopathological data for research purposes, as well as construction of tissue microarrays from archived diagnostic left-over tissues, was approved by the local laws (HmbKHG, §12,1) and by the local ethics committee (Ethics Commission of Hamburg, WF-049/09 and PV3652). All study was carried out in compliance with the Helsinki Declaration.

Immunohistochemistry. Freshly cut TMA sections were analyzed in one day and in one experiment. Primary antibody specific for LIG4 (rabbit, at 1:150 dilution; Sigma) was applied, slides were deparaffinized and exposed to heatinduced antigen retrieval for $5 \mathrm{~min}$ in an autoclave at $121^{\circ} \mathrm{C}$ in 7.8 Tris-EDTA-citrate buffer. Bound antibody was then visualized using the EnVision kit (Dako). LIG4 expression was homogeneous within individual cancer tissue samples. Assessment of immunostaining was thus limited to recording
Table I. Composition of the prognosis tissue microarray containing 11,152 prostate cancer specimens.

\begin{tabular}{|c|c|c|}
\hline & \multicolumn{2}{|c|}{ No. of patients } \\
\hline & $\begin{array}{l}\text { Study cohort on } \\
\text { tissue microarray } \\
\quad(n=11,152)\end{array}$ & $\begin{array}{l}\text { Biochemical relapse } \\
\text { among categories } \\
(n=1,824)\end{array}$ \\
\hline \multicolumn{3}{|l|}{$\begin{array}{l}\text { Follow-up } \\
\text { (month) }\end{array}$} \\
\hline Mean & 53.4 & - \\
\hline Median & 36.8 & - \\
\hline \multicolumn{3}{|l|}{ Age (years) } \\
\hline$<50$ & 318 & 49 \\
\hline $50-60$ & 2,768 & 460 \\
\hline $60-70$ & 6,548 & 1,081 \\
\hline$>70$ & 1,439 & 232 \\
\hline \multicolumn{3}{|c|}{$\begin{array}{l}\text { Pretreatment PSA } \\
(\mathrm{ng} / \mathrm{ml})\end{array}$} \\
\hline$<4$ & 1,407 & 142 \\
\hline $4-10$ & 6,735 & 827 \\
\hline $10-20$ & 2,159 & 521 \\
\hline$>20$ & 720 & 309 \\
\hline \multicolumn{3}{|c|}{$\begin{array}{l}\text { pT stage } \\
\text { (AJCC 2002) }\end{array}$} \\
\hline $\mathrm{pT} 2$ & 7,370 & 570 \\
\hline pT3a & 2,409 & 587 \\
\hline pT3b & 1,262 & 618 \\
\hline $\mathrm{pT} 4$ & 63 & 49 \\
\hline \multicolumn{3}{|c|}{ Gleason grade } \\
\hline$\leq 3+3$ & 2,859 & 193 \\
\hline $3+4$ & 6,183 & 849 \\
\hline $4+3$ & 1,565 & 573 \\
\hline$\geq 4+4$ & 482 & 208 \\
\hline \multicolumn{3}{|l|}{ pN stage } \\
\hline pNO & 6,117 & 1,126 \\
\hline $\mathrm{pN}+$ & 561 & 291 \\
\hline \multicolumn{3}{|c|}{ Surgical margin } \\
\hline Negative & 8,984 & 1,146 \\
\hline Positive & 1,970 & 642 \\
\hline
\end{tabular}

Numbers do not always add up to 11,152 in the different categories because of cases with missing data; AJCC, American Joint Committee on Cancer.

the staining intensity in 4 categories: Negative, weak, moderate and strong immunostaining. Staining levels in cancer cells were defined by estimating each spot by one person experienced in TMA analyses.

Statistics. Statistical calculations were performed with JPM 9 software (SAS Institute Inc., Cary, NC, USA). Contingency 

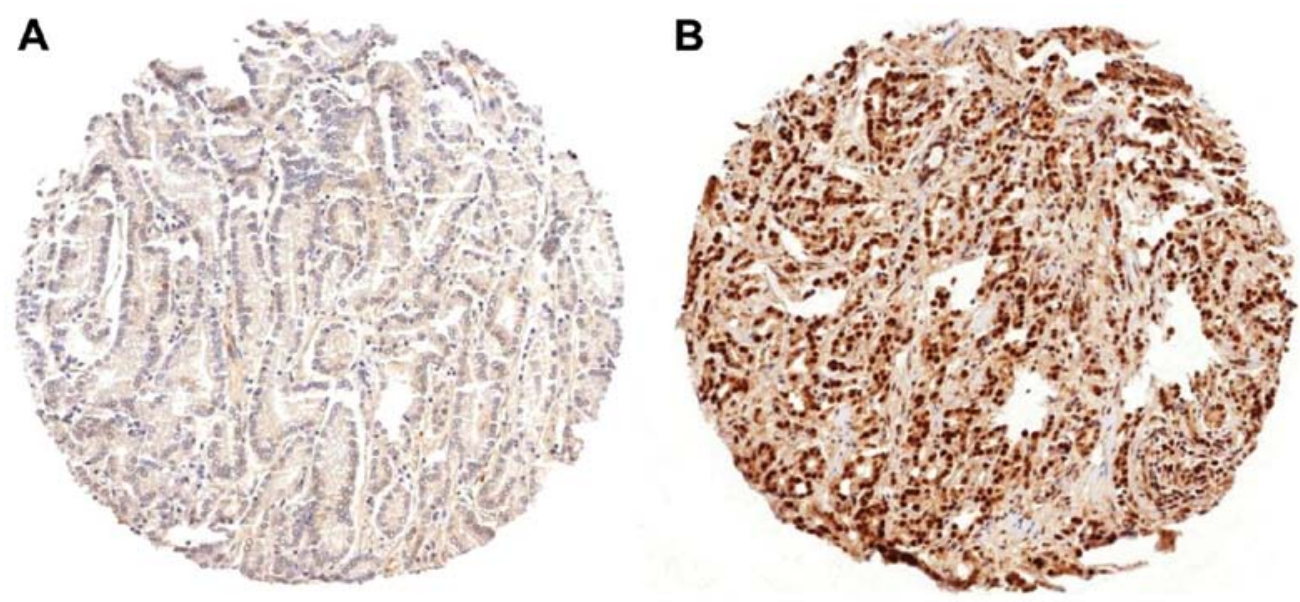

Figure 1. Representative pictures of (A) negative and (B) positive LIG4 immunostaining in prostate cancer. LIG4, ligase IV.

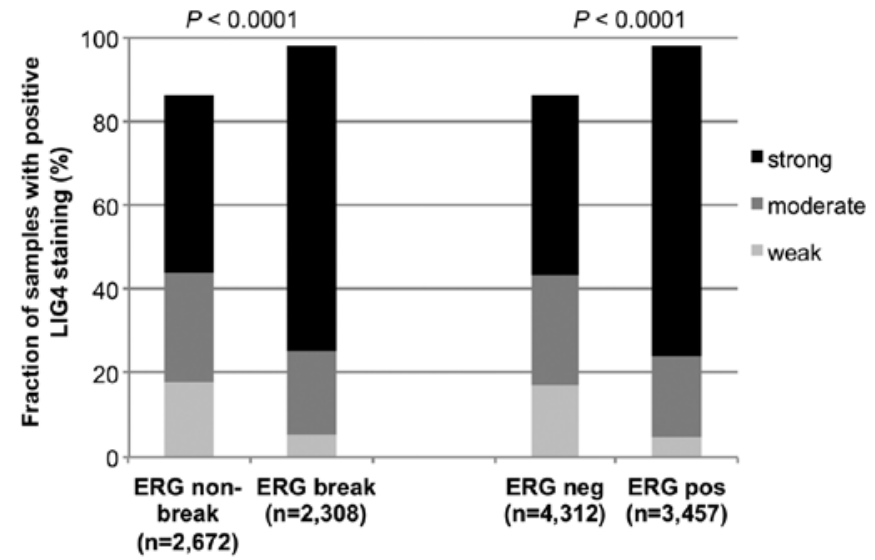

Figure 2. Relationship of LIG4 expression with ERG status probed by FISH and IHC. LIG4, ligase IV; FISH, fluorescence in situ hybridization.

tables and the chi-square $\left(\mathrm{x}^{2}\right)$ test were performed to search for associations between molecular parameters and tumor phenotype. Survival curves were calculated according to Kaplan-Meier. The log-rank test was applied to detect significant survival differences between groups. COX proportional hazards regression analysis was performed to test the statistical independence and significance between pathological, molecular and clinical variables.

\section{Results}

Technical aspects. A total of 2,493 of 11,152 arrayed tissue samples $(22 \%)$ were non-informative for LIG4 analysis due to the complete lack of tissue or absence of unequivocal cancer cells.

LIG4 immunohistochemistry. LIG4 expression was localized in the nucleus of the cells with increased intensities in malignant as compared to benign prostate epithelium. A total of 7,905 of our 8,663 interpretable prostate cancers $(91 \%)$ showed positive LIG4 expression, which was considered weak in $12 \%$, moderate in $23 \%$ and strong in $56 \%$ of cases. Representative images are given in Fig. 1. Strong LIG4 expres- sion was positive significantly linked to high Gleason score $(\mathrm{P}<0.0001)$ and positive nodal involvement $(\mathrm{P}=0.03)$, but not to high preoperative PSA levels, advanced tumor stage and positive surgical margin when all cancers were analyzed.

LIG4 versus ERG status. To evaluate whether LIG4 expression is linked to $E R G$ status, we used our pre-existing database including data on TMPRSS2:ERG fusion status obtained by FISH in 4,980 patients and by IHC in 7,769 tumors for which LIG4 immunostaining was also available. Strong LIG4 expression was significantly more frequent in fusion-type $(1,677 / 2,308,73 \%)$ than in non-fusion-type prostate cancers $(1,121 / 2,672,42 \%, \mathrm{P}<0.0001$, Fig. 2$)$ as analyzed by FISH. Accordingly, strong LIG4 staining occurred more often in ERG expression positive $(2,569 / 3,457,74 \%)$ than in ERG expression negative prostate cancers $(1,849 / 4,312,43 \%$, $\mathrm{P}<0.0001$, Fig. 2). Since increased LIG4 expression was more frequent in fusion-type prostate cancers, the associations of LIG4 expression with tumor phenotype and clinical cancer features were separately analyzed in both non-fusion and fusion-type prostate cancers (Tables II and III). In both non-fusion and fusion-type prostate cancers, strong LIG4 expression was significantly linked to advanced Gleason grade $(\mathrm{P}<0.001)$. There was only a marginal relationship between LIG4 expression and $\mathrm{pT}$ stage which reached significance in ERG-negative cancers $(\mathrm{P}=0.0005$, Table II).

Associations with genomic deletions in non-fusion and fusion-type prostate cancers. Previous studies provided evidence for distinct molecular subgroups of prostate cancers defined by TMPRSS2:ERG fusions and several genomic deletions. We and others have described a strong link of deletions at $5 \mathrm{q} 21$ and $6 \mathrm{q} 15$ to non-fusion type and of deletions at PTEN and 3 p13 to fusion-type prostate cancers (25-27,29-31). To study, whether LIG4 expression may be particularly linked to one of these genomic deletions, LIG4 data were compared with pre-existing findings on PTEN, 3p13, 6q15 and 5q21 deletions. In the analysis of all tumors, LIG4 staining was significantly associated with deletions of PTEN and 3p13 $(\mathrm{P}<0.0001$ and $\mathrm{P}=0.02$, Fig. 3). A subsequent subgroup analysis of non-fusion and fusion-type prostate cancers revealed that the significant 
Table II. Associations between LIG4 expression and clinicopathological parameters in the subgroup of ERG-negative prostate cancer.

\begin{tabular}{|c|c|c|c|c|c|c|}
\hline & \multirow[b]{2}{*}{ Evaluable (N) } & \multicolumn{4}{|c|}{ LIG4 IHC result (\%) } & \multirow[b]{2}{*}{ P-value } \\
\hline & & Negative & Weak & Moderate & Strong & \\
\hline All cancers & 4,312 & 14 & 17 & 26 & 43 & \\
\hline \multicolumn{7}{|l|}{ Tumor stage } \\
\hline pT2 & 2,872 & 15 & 18 & 25 & 41 & 0.0005 \\
\hline pT3a & 887 & 12 & 15 & 28 & 45 & \\
\hline $\mathrm{pT} 3 \mathrm{~b}$ & 513 & 9 & 16 & 26 & 49 & \\
\hline pT4 & 28 & 21 & 11 & 29 & 39 & \\
\hline \multicolumn{7}{|c|}{ Gleason grade } \\
\hline$\leq 3+3$ & 987 & 20 & 25 & 23 & 32 & $<0.0001$ \\
\hline $3+4$ & 2,036 & 13 & 16 & 27 & 44 & \\
\hline $4+3$ & 711 & 10 & 12 & 28 & 50 & \\
\hline$\geq 4+4$ & 238 & 8 & 12 & 25 & 55 & \\
\hline \multicolumn{7}{|c|}{ Lymph node metastasis } \\
\hline NO & 2,469 & 13 & 16 & 26 & 45 & 0.006 \\
\hline $\mathrm{N}+$ & 226 & 7 & 13 & 26 & 54 & \\
\hline \multicolumn{7}{|c|}{ Surgical margin } \\
\hline Negative & 3,443 & 14 & 17 & 26 & 42 & 0.36 \\
\hline Positive & 791 & 12 & 17 & 27 & 44 & \\
\hline
\end{tabular}

LIG4, ligase IV.

Table III. Associations between LIG4 expression and clinicopathological parameters in the subgroup of ERG-positive prostate cancer.

\begin{tabular}{|c|c|c|c|c|c|c|}
\hline & \multirow[b]{2}{*}{ Evaluable (N) } & \multicolumn{4}{|c|}{ LIG4 IHC result (\%) } & \multirow[b]{2}{*}{ P-value } \\
\hline & & Negative & Weak & Moderate & Strong & \\
\hline All cancers & 3,457 & 2 & 5 & 19 & 74 & \\
\hline \multicolumn{7}{|l|}{ Tumor stage } \\
\hline pT2 & 2,039 & 2 & 5 & 18 & 74 & 0.19 \\
\hline pT3a & 951 & 1 & 5 & 18 & 76 & \\
\hline pT3b & 430 & 2 & 3 & 23 & 72 & \\
\hline pT4 & 20 & 0 & 10 & 15 & 75 & \\
\hline \multicolumn{7}{|c|}{ Gleason grade } \\
\hline$\leq 3+3$ & 792 & 3 & 8 & 19 & 70 & 0.0005 \\
\hline $3+4$ & 2,038 & 2 & 4 & 18 & 76 & \\
\hline $4+3$ & 490 & 1 & 4 & 18 & 76 & \\
\hline$\geq 4+4$ & 114 & 2 & 3 & 24 & 72 & \\
\hline \multicolumn{7}{|c|}{ Lymph node metastasis } \\
\hline NO & 1,932 & 2 & 4 & 18 & 76 & 0.01 \\
\hline $\mathrm{N}+$ & 204 & 3 & 3 & 25 & 68 & \\
\hline \multicolumn{7}{|c|}{ Surgical margin } \\
\hline Negative & 2,707 & 2 & 5 & 19 & 74 & 0.69 \\
\hline Positive & 691 & 1 & 5 & 19 & 74 & \\
\hline
\end{tabular}

LIG4, ligase IV. 


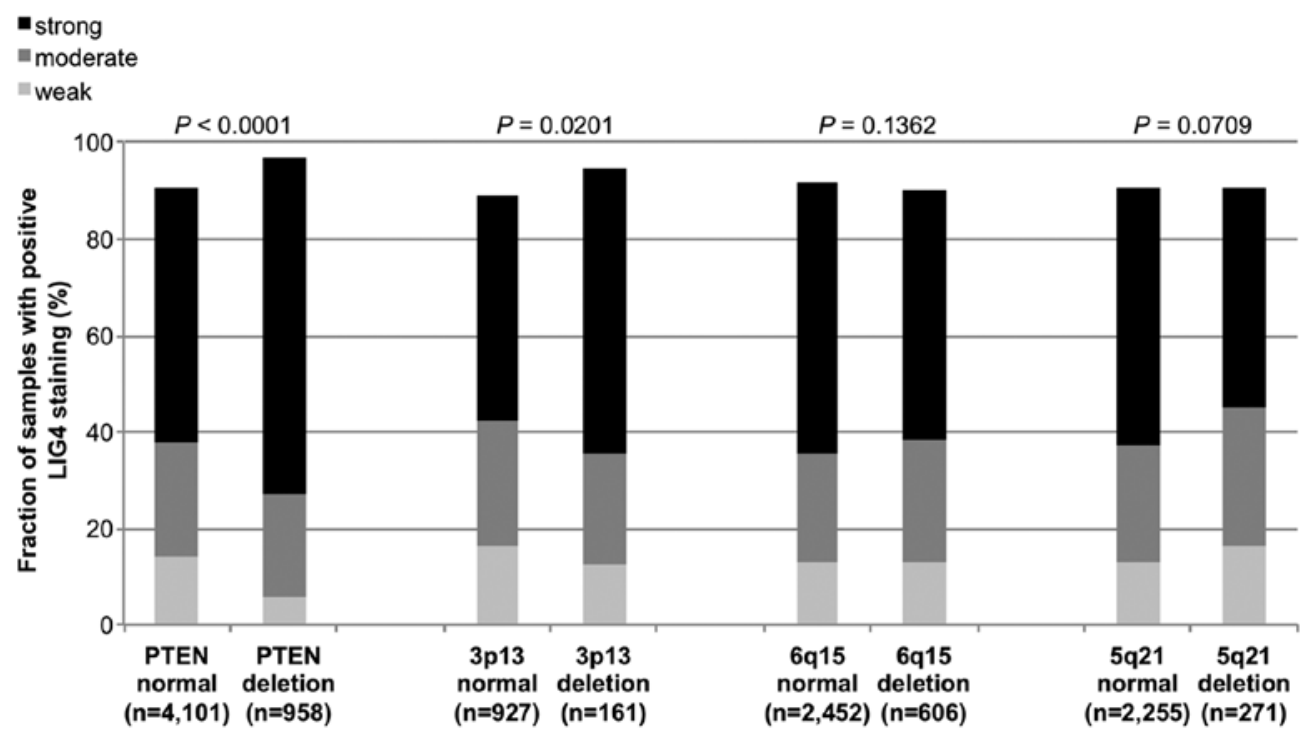

Figure 3. LIG4 expression vs. PTEN, 3p13, 6q15 and 5q21 deletions probed by FISH analysis in all cancers. LIG4, ligase IV; FISH, fluorescence in situ hybridization.

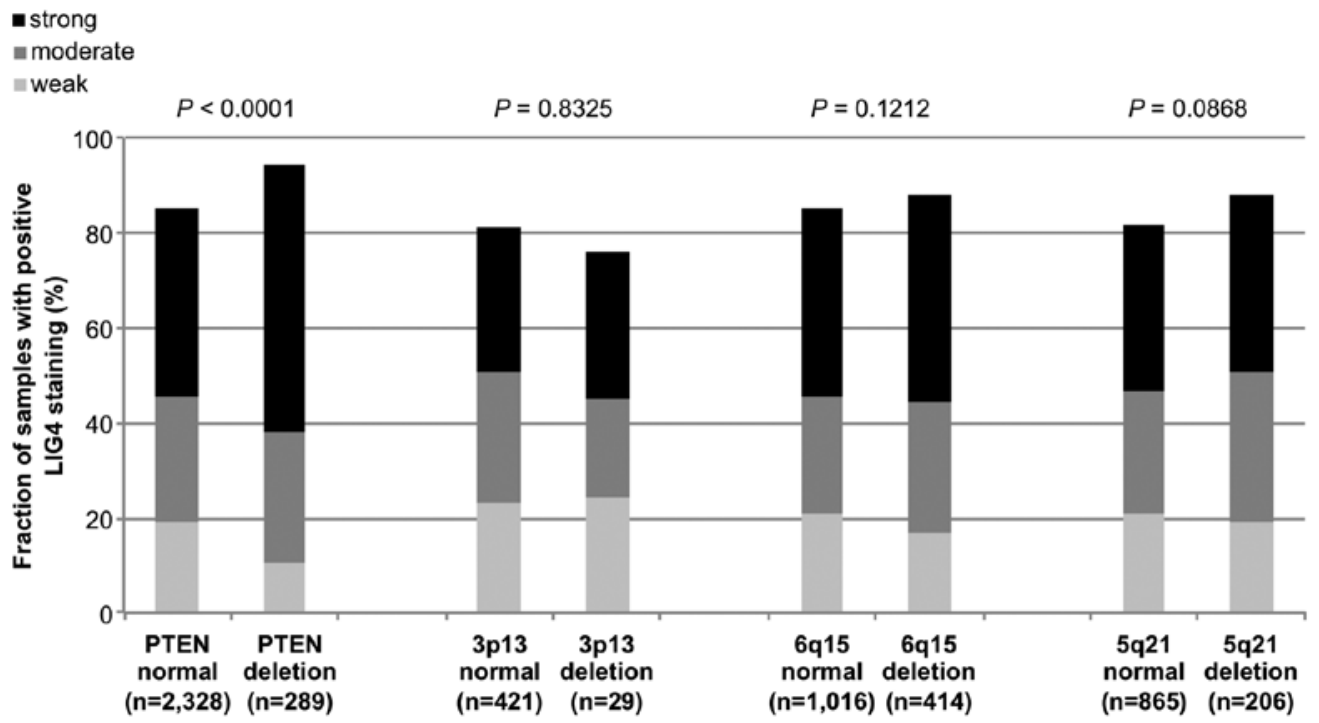

Figure 4. LIG4 expression vs. PTEN, 3p13, 6q15 and 5q21 deletions probed by FISH analysis in the ERG-negative subset by IHC. LIG4, ligase IV; FISH, fluorescence in situ hybridization.

association of increased LIG4 expression with PTEN deletions retained significance in both non-fusion and fusion-type prostate cancers $(\mathrm{P}<0.0001$ and $\mathrm{P}=0.003$, Figs. 4 and 5) while all other deletions were unrelated or only marginally related to LIG4 expression.

Clinical impact of LIG4. Follow-up data were available for 7,539 patients with informative LIG4 data. Strong prognostic impact of the Gleason grade provides indirect evidence for the overall validity of our follow-up data $(\mathrm{P}<0.0001$, Fig. 6A). Increased LIG4 staining was tightly linked to early biochemical recurrence when all cancers $(\mathrm{P}<0.0001$, Fig. 6B) or the subset of ERG-negative $(\mathrm{P}=0.0004$, Fig. 6C) and ERG-positive ( $\mathrm{P}=0.006$, Fig. 6D) prostate cancers were analyzed. Given the strong link of LIG4 expression to PTEN deletions which are known to be prognostically relevant (27), further analysis was performed according to the PTEN deletion status. These results demonstrated that LIG4 expression lost its prognostic impact in both subgroups of PTEN-non-deleted ( $\mathrm{P}=0.23$, Fig. 6E) and PTEN-deleted prostate cancers $(\mathrm{P}=0.24$, Fig. $6 \mathrm{~F})$.

Multivariate analysis. Four independent multivariate analyses were performed evaluating the clinical relevance of LIG4 expression in different scenarios (Table IV). Scenario 1 was utilizing all post-operatively available parameters including $\mathrm{pT}$, $\mathrm{pN}$, margin status, preoperative PSA value and Gleason grade obtained on the resected prostate. Scenario 2 was utilizing all postoperatively available parameters with the exception of nodal status. The rational for this approach was that lymphadenectomy is not a routine procedure in the surgical therapy of prostate cancer and that excluding $\mathrm{pN}$ in multivariate analysis 


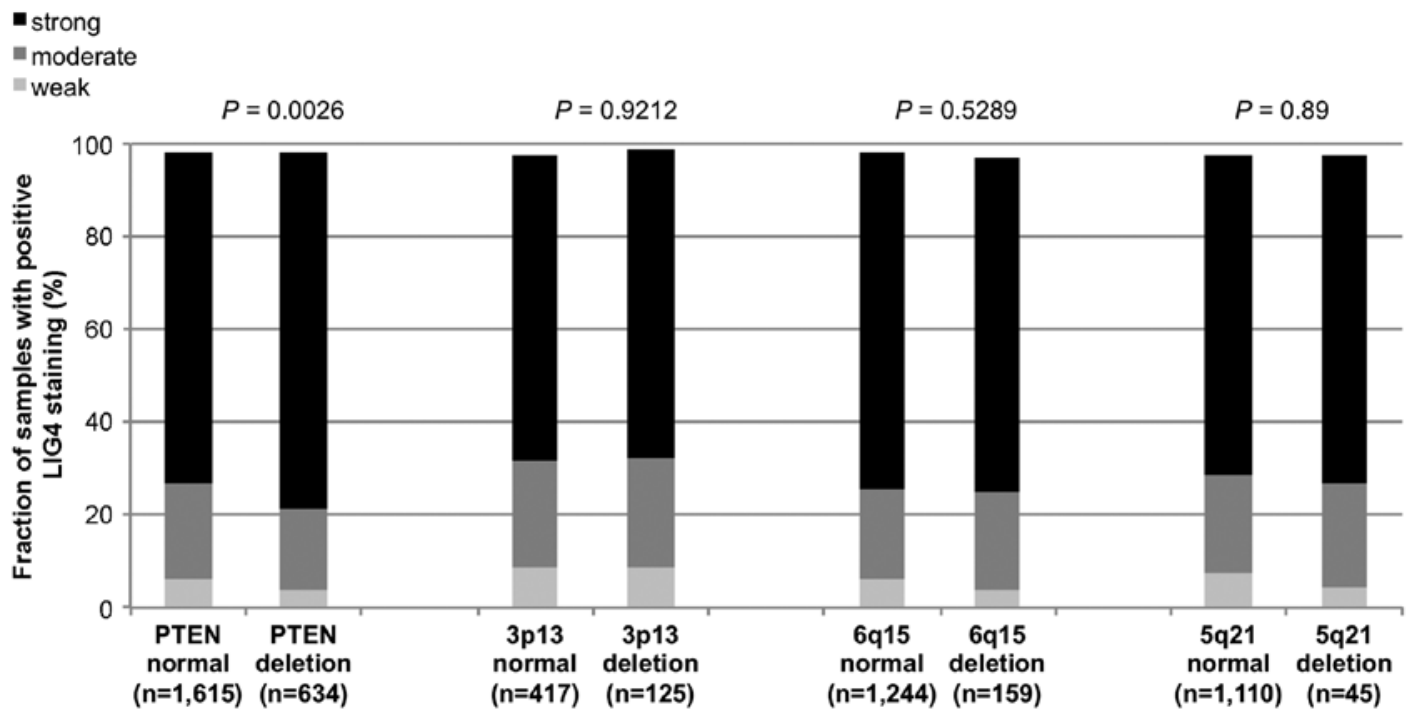

Figure 5. LIG4 expression vs. PTEN, 3p13, 6q15 and 5q21 deletions probed by FISH analysis in the ERG-positive subset by IHC. LIG4, ligase IV; FISH, fluorescence in situ hybridization.

A

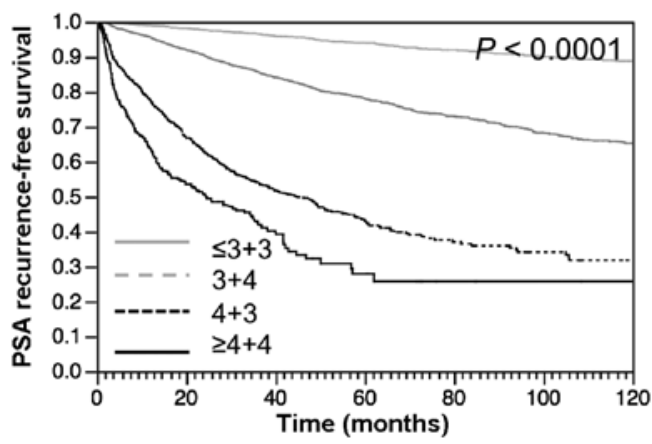

C

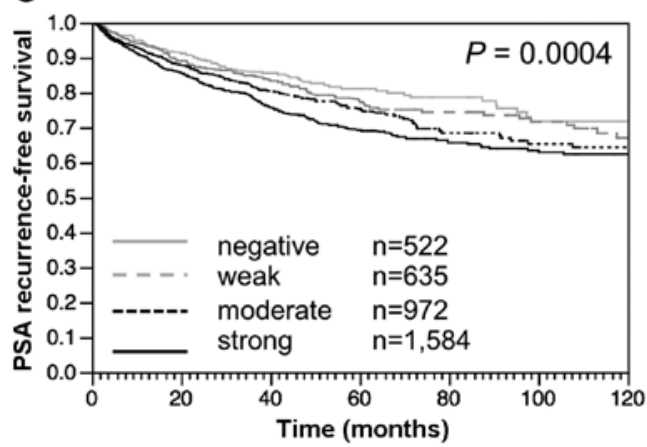

E

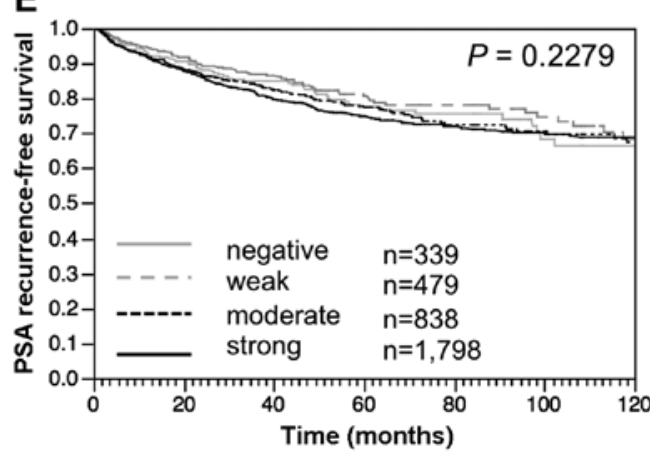

B

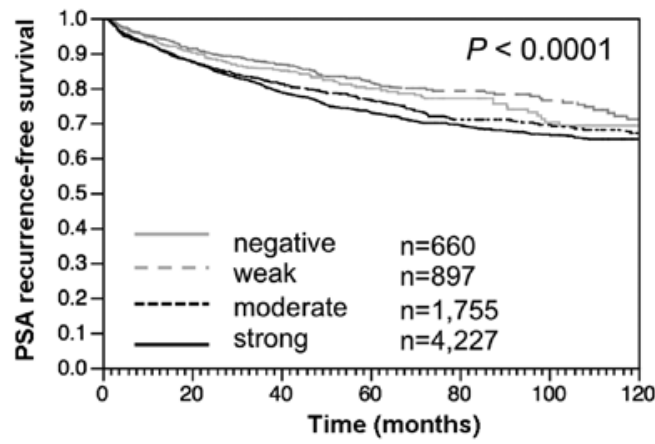

D

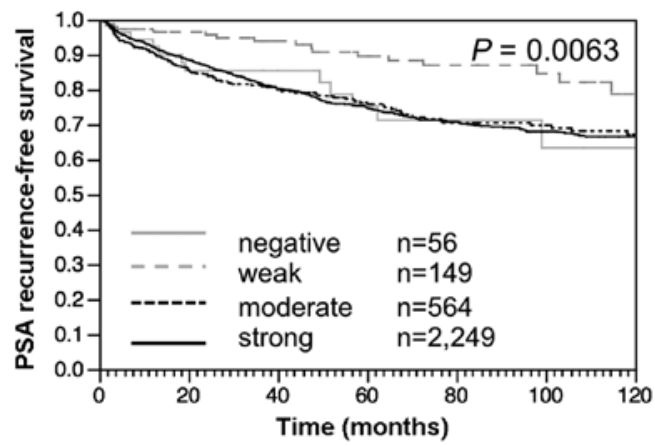

$\mathbf{F}$

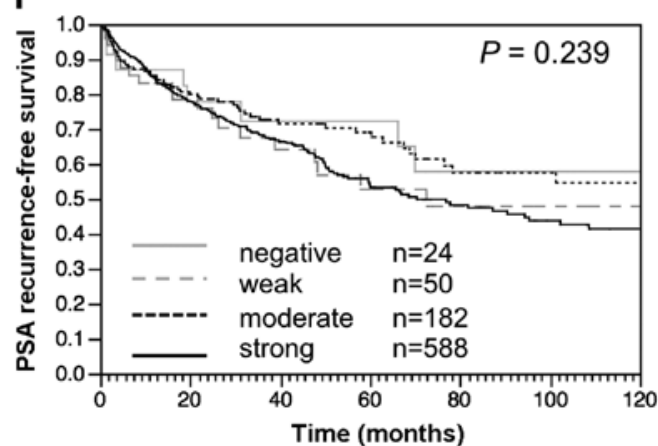

Figure 6. Kaplan-Meier plots for PSA recurrence-free survival. (A) Relationship with Gleason grade. (B) Association of LIG4 expression with biochemical recurrence in all prostate cancers $(\mathrm{n}=7,539)$, (C) ERG-negative subset (n=3,713), (D) ERG-positive subset $(\mathrm{n}=3,018),(\mathrm{E})$ PTEN-non-deleted subset (n=3,454) and (F) PTEN-deleted subset (n=844). LIG4, ligase IV. 
Table IV. Multivariate analysis including LIG4 expression status in all prostate cancers, the ERG-negative and ERG-positive subset.

\begin{tabular}{|c|c|c|c|c|c|c|c|c|c|c|}
\hline \multirow[b]{2}{*}{ Group } & \multirow[b]{2}{*}{ Scenario } & \multicolumn{9}{|c|}{ P-value } \\
\hline & & $\begin{array}{l}\text { Evaluable } \\
\text { (N) }\end{array}$ & $\begin{array}{c}\text { Preoperative } \\
\text { PSA level }\end{array}$ & pT stage & cT stage & $\begin{array}{l}\text { Gleason grade } \\
\text { prostatectomy }\end{array}$ & $\begin{array}{c}\text { Gleason grade } \\
\text { biopsy }\end{array}$ & pN stage & R status & $\begin{array}{c}\text { LIG4 } \\
\text { expression }\end{array}$ \\
\hline \multicolumn{11}{|l|}{ All } \\
\hline & 1 & 4,446 & $<0.0001$ & $<0.0001$ & - & $<0.0001$ & - & $<0.0001$ & $<0.0001$ & 0.25 \\
\hline & 2 & 7,364 & $<0.0001$ & $<0.0001$ & - & $<0.0001$ & - & - & $<0.0001$ & 0.03 \\
\hline & 3 & 7,236 & $<0.0001$ & - & $<0.0001$ & $<0.0001$ & - & - & - & 0.04 \\
\hline & 4 & 7,131 & $<0.0001$ & - & $<0.0001$ & - & $<0.0001$ & - & - & 0.03 \\
\hline \multicolumn{11}{|c|}{ ERG-negative subset } \\
\hline & 1 & 2,248 & $<0.0001$ & $<0.0001$ & - & $<0.0001$ & - & $<0.0001$ & 0.01 & 0.8 \\
\hline & 2 & 3,626 & $<0.0001$ & $<0.0001$ & - & $<0.0001$ & - & - & $<0.0001$ & 0.65 \\
\hline & 3 & 3,592 & $<0.0001$ & - & 0.0002 & $<0.0001$ & - & - & - & 0.42 \\
\hline & 4 & 3,543 & $<0.0001$ & - & $<0.0001$ & - & $<0.0001$ & - & - & 0.12 \\
\hline \multicolumn{11}{|c|}{ ERG-positive subset } \\
\hline & 1 & 1,802 & 0.0301 & $<0.0001$ & - & $<0.0001$ & - & 0.07 & 0.006 & 0.21 \\
\hline & 2 & 2,949 & 0.0009 & $<0.0001$ & - & $<0.0001$ & - & - & $<0.0001$ & 0.01 \\
\hline & 3 & 2,868 & $<0.0001$ & - & $<0.0001$ & $<0.0001$ & - & - & - & 0.02 \\
\hline & 4 & 2,821 & $<0.0001$ & - & $<0.0001$ & - & $<0.0001$ & - & & 0.007 \\
\hline
\end{tabular}

LIG4, ligase IV.

increases case numbers. The next 2 scenarios tried to better model the preoperative situation. Scenario 3 included the LIG4 expression, preoperative PSA, clinical stage (cT) and the Gleason grade obtained on the prostatectomy specimen. However, the preoperative determination of the Gleason grade in tumors is subject to sampling errors and therefore results in under grading in more than one third of cases. Because the postoperative Gleason grade thus varies from the preoperative Gleason grade, another multivariate analysis was added as scenario 4. In this scenario, the preoperative Gleason grade obtained on the original biopsy was combined with preoperative PSA, clinical stage and LIG4 expression. The analyses demonstrate a tendency towards independent prognostic relevance of LIG4 expression in 'preoperative' scenarios, especially in ERG-fusion-positive prostate cancers (Table IV).

\section{Discussion}

Our study identified increased LIG4 as a predictor of an increased risk for early PSA recurrence in prostate cancer.

The successful immunohistochemical analysis of $>10,000$ prostate cancers revealed that LIG4 is abundantly present in prostate cancer as it was detectable in $>90 \%$ of all cancers using the IHC protocol. Our observation of abundant LIG4 expression is consistent with its essential role for survival of dividing cells. Impaired NHEJ, for example by loss of LIG4, is embryonic lethal (32-34). Since DSB is an inherent side effect of DNA replication, it occurs most frequently in rapidly dividing cells such as developing tissues or cancer cells (35), but can also be induced replication-independently by oxidative stress or exogenous noxes like ionizing radia- tion (36). Increased LIG4 staining intensities in cancerous compared to benign prostate epithelium is consistent with the generally increased proliferation rate of prostate cancer cells as compared to normal prostatic glands.

It is a distinct advantage of the tissue microarray technique, that hundreds or thousands of tissue samples can be analyzed in one day in one experiment by using one set of reagents at absolutely identical concentrations, temperatures and exposure times. Maximal experimental standardization is a prerequisite for the distinction of subtle expression differences of proteins that are abundantly expressed in prostate cancer such as LIG4. The parallel analysis of thousands of tumors typically enables the identification of differences between subgroups although the immunohistochemical analysis of a number of individual samples may be impaired by either too extensive or inefficient formalin fixation. The comparison between different LIG4 staining levels and tumor phenotype or PSA recurrence revealed significant associations in our study. Particularly, there was a significant association of strong LIG4 expression with early biochemical recurrence.

Another major aim of our study was to analyze the relationship with key genomic alterations in prostate cancer, including gene fusions and chromosomal deletions, all of which are potentially due to or facilitated by impaired DNA repair mechanisms. About half of prostate cancers carry gene fusions linking the androgen-regulated gene TMPRSS 2 with transcription factors of the ETS family (37). In consequence of the most frequent of these rearrangements, the TMPRSS2:ERG fusion, the expression of ERG becomes androgen-regulated and ERG massively overexpressed. Our data demonstrate that strong LIG4 immunostaining is significantly associated 
with fusion-type prostate cancer. High LIG4 expression was almost twice as frequent in 'fusion-type' than in 'non-fusion-type' prostate cancers. Finding this association by two independent approaches for ERG fusion detection (IHC/ FISH) largely excludes a false positive association due to inefficient expression for both LIG4 and ERG in a subset of damaged non-reactive tissues.

TMPRSS2:ERG fusion is caused by either translocation or deletion of a large $(3.7 \mathrm{Mb})$ chromosome fragment separating the TMPRSS 2 and $E R G$ gene loci. Androgen signaling, which promotes recruitment of androgen receptor (AR) and topoisomerase II $\beta$ (TOP2B) to sites of TMPRSS2:ERG breakpoints, has been identified as the underlying trigger driving fusion (38). TOP2B resolves DNA topologic constraints eventually occurring during DNA movement by a transient DSB allowing for passing one DNA strand through another (39). As a consequence, components of the DSB breakage repair machinery are required for repair of these transient DSB (40), with LIG4 catalyzing the final step of ligation of the open DNA ends (41). The strong association between $E R G$ fusion and LIG4 overexpression in our study thus reflects the constitutive activation of the DSB repair machinery in cancers with elevated androgen signaling activity.

Of note, structural rearrangements are not limited to $E R G$ fusion-positive cancers but do also occur in $E R G$-negative tumors. A number of large interstitial deletions have been identified, some of which can be linked to $E R G$-positive (including for example deletions at 3p13 and the PTEN locus at 10q23), or $E R G$-negative cancers (for example deletions at $5 q 21,6 q 15$ or 2 q23) $(21,25-27,31,42,43)$. Likewise, balanced as well as imbalanced translocations have been detected in both $E R G$-positive and $E R G$-negative tumors $(29,20)$. Since interstitial deletions, like translocations, can be caused by DSB (44), it was not surprising that also $40 \%$ of $E R G$-negative cancers showed LIG4 expression indicating activated DSB repair. The overall lack of a clear-cut association between presence of deletions and LIG4 expression, however, indicates that many deletions might also occur for other reasons than topoisomerase-driven DSB. For example, deletions may also develop by DNA breakage during chromosome segregation in dividing cells. Berger et al (29) reported multiple fusions connecting segments from different chromosomes to 'closed chains'. Such fused chromosomes will inevitably break randomly if the kinetochores are pulled into the daughter cells by the microtubules of the spindle cell apparatus. Also, complex rearrangements have been reported from dicentromeric chromosomes, which undergo breakage during cell division, leaving one daughter cell with a deletion and the other with a duplication and inversion (45).

Deletion of PTEN was the only aberration linked to strong LIG4 expression independently from the $E R G$ status. This suggests that PTEN deletion may frequently develop through topoisomerase-mediated DSB and subsequent LIG4 recruitment. PTEN deletion is typically small, often involving only the gene locus and small $(<2 \mathrm{Mb})$ adjacent segments (unpublished data). This is in contrast to almost all other deletions found in prostate cancer, which are typically large and encompass $>10 \mathrm{Mb}$ (31). It is possible, that PTEN deletion is driven by a similar, topoisomerase and LIG4-dependent DSB mechanism than $E R G$ fusion. The strong association between PTEN deletion and LIG4 may, thus be attributable, to a specific mechanism requiring increased levels of LIG4.

Interestingly, LIG4 overexpression was equally linked to early PSA recurrence in ERG-positive and ERG-negative cancers. This association was not surprising given that LIG4 expression indicates active DSB repair. It can be assumed that tumors with increased repair activity have a high number of DSB, and thus a high likelihood of repair errors eventually resulting in alterations of cancer relevant genes and overall genetic instability. It has been shown before that increased genetic instability is linked to poor outcome in many solid cancer types $(46,47)$.

Our TMA containing $>10,000$ prostate cancer specimens represents a suitable system for assessing potential prognostic markers. In earlier studies we successfully validated all established prognostic biomarkers in prostate cancer such as nuclear p53 accumulation (48) and Ki67 labeling index (49) on smaller prostate cancer TMAs, and identified several other prognostic biomarkers such as deletions at $8 \mathrm{p}(50), 6 \mathrm{q} 15$ and PTEN (27) or CRISP3 expression (51). It is noteworthy, that our approach of analyzing molecular features on one-minute tissue specimen per patient on a TMA measuring $0.6 \mathrm{~mm}$ in diameter represents a close model of molecularly analyzing core needle biopsies. Core needle biopsies enable the molecular analysis of comparable amounts of tissue as on a TMA. The optimal biomarker evaluation strategy would include the molecular analysis of the original needle biopsy of a patient and compare its prognostic value with preoperative Gleason grade obtained on the same biopsy as well as the preoperative PSA value. For practical purposes, this approach is not feasible because preoperative biopsies are typically distributed over many different centers and not available for studies. Moreover, even if available, these precious core needle biopsies would be exhausted after only few studies. A convoluted approach evaluating multiple different scenarios was thus utilized in this study. Overall, these data suggest a prognostic relevance of LIG4 expression in prostate cancer that may be independent of clinical and histopathological features available in a preoperative situation.

In summary, the significant link of increased LIG4 levels with aggressiveness in a series of $>11,000$ prostate cancers suggests that LIG4 analysis may prove instrumental as a prognostic biomarker either alone or in combination with other factors. Morover, our data demonstrate, that balanced translocations and gene fusions like TMPRSS2:ERG are strongly linked to LIG4-dependend DSB repair, whereas 'simple' deletions may often arise through DSB/LIG4 independent mechanisms.

\section{Acknowledgements}

We thank Julia Schumann, Sünje Seekamp and Inge Brandt for the excellent technical assistance.

\section{References}

1. Jemal A, Bray F, Center MM, Ferlay J, Ward E and Forman D: Global cancer statistics. CA Cancer J Clin 61: 69-90, 2011.

2. Galanty Y, Belotserkovskaya R, Coates J, Polo S, Miller KM and Jackson SP: Mammalian SUMO E3-ligases PIAS1 and PIAS4 promote responses to DNA double-strand breaks. Nature 462: 935-939, 2009. 
3. Ferguson DO, Sekiguchi JM, Chang S, Frank KM, Gao Y, DePinho RA and Alt FW: The nonhomologous end-joining pathway of DNA repair is required for genomic stability and the suppression of translocations. Proc Natl Acad Sci USA 97: 6630-6633, 2000.

4. Vanasse GJ, Halbrook J, Thomas S, Burgess A, Hoekstra MF, Disteche CM and Willerford DM: Genetic pathsway to recurrent chromosome translocations in murine lymphoma involves $\mathrm{V}(\mathrm{D}) \mathrm{J}$ recombinase. J Clin Invest 103: 1669-1675, 1999.

5. Gao N, Keane MJ, Ong T and Wallace WE: Effects of simulated pulmonary surfactant on the cytotoxicity and DNA-damaging activity of respirable quartz and kaolin. J Toxicol Environ Health A 60: 153-167, 2000.

6. Nussenzweig A, Chen C, da Costa Soares V, Sanchez M, Sokol K, Nussenzweig MC and Li GC: Requirement for Ku80 in growth and immunoglobulin V(D)J recombination. Nature 382: 551-555, 1996.

7. Zhu C, Bogue MA and Roth DB: Thymocyte differentiation in gamma-irradiated severe-combined immunodeficient mice: Characterization of intermediates and products of V(D)J recombination at the $\mathrm{T}$ cell receptor alpha locus. Eur J Immunol 26 : 2859-2865, 1996.

8. Gu Y, Jin S, Gao Y, Weaver DT and Alt FW: Ku70-deficient embryonic stem cells have increased ionizing radiosensitivity, defective DNA end-binding activity, and inability to support V(D)J recombination. Proc Natl Acad Sci USA 94: 8076-8081, 1997.

9. Ouyang H, Nussenzweig A, Kurimasa A, Soares VC, Li X, Cordon-Cardo C, Li W, Cheong N, Nussenzweig M, Iliakis G, et al: $\mathrm{Ku} 70$ is required for DNA repair but not for $\mathrm{T}$ cell antigen receptor gene recombination in vivo. J Exp Med 186: 921-929, 1997.

10. Garcia AM, Salomon RN, Witsell A, Liepkalns J, Calder RB, Lee M, Lundell M, Vijg J and McVey M: Loss of the bloom syndrome helicase increases DNA ligase 4-independent genome rearrangements and tumorigenesis in aging Drosophila. Genome Biol 12: R121, 2011

11. Kapusta A, Matsuda A, Marmignon A, Ku M, Silve A, Meyer E, Forney JD, Malinsky S and Bétermier M: Highly precise and developmentally programmed genome assembly in Paramecium requires ligase IV-dependent end joining. PLoS Genet 7 e1002049, 2011.

12. Chistiakov DA, Voronova NV and Chistiakov PA: Genetic variations in DNA repair genes, radiosensitivity to cancer and susceptibility to acute tissue reactions in radiotherapy-treated cancer patients. Acta Oncol 47: 809-824, 2008.

13. Roddam PL, Rollinson S, O'Driscoll M, Jeggo PA, Jack A and Morgan GJ: Genetic variants of NHEJ DNA ligase IV can affect the risk of developing multiple myeloma, a tumour characterised by aberrant class switch recombination. J Med Genet 39: 900-905, 2002

14. Liu Y, Shete S, Etzel CJ, Scheurer M, Alexiou G, Armstrong G, Tsavachidis S, Liang FW, Gilbert M, Aldape K, et al: Polymorphisms of LIG4, BTBD2, HMGA2, and RTEL1 genes involved in the double-strand break repair pathway predict glioblastoma survival. J Clin Oncol 28: 2467-2474, 2010.

15. Kuschel B, Auranen A, McBride S, Novik KL, Antoniou A, Lipscombe JM, Day NE, Easton DF, Ponder BA, Pharoah PD, et al: Variants in DNA double-strand break repair genes and breast cancer susceptibility. Hum Mol Genet 11: 1399-1407, 2002.

16. Sakiyama T, Kohno T, Mimaki S, Ohta T, Yanagitani N, Sobue T, Kunitoh H, Saito R, Shimizu K, Hirama C, et al: Association of amino acid substitution polymorphisms in DNA repair genes TP53, POLI, REV1 and LIG4 with lung cancer risk. Int J Cancer 114: 730-737, 2005.

17. Li R, Li Y, Fang X, Yang H, Wang J, Kristiansen K and Wang J: SNP detection for massively parallel whole-genome resequencing. Genome Res 19: 1124-1132, 2009.

18. Pugh TJ, Keyes M, Barclay L, Delaney A, Krzywinski M, Thomas D, Novik K, Yang C, Agranovich A, McKenzie M, et al: Sequence variant discovery in DNA repair genes from radiosensitive and radiotolerant prostate brachytherapy patients. Clin Cancer Res 15: 5008-5016, 2009.

19. Damaraju S, Murray D, Dufour J, Carandang D, Myrehaug S, Fallone G, Field C, Greiner R, Hanson J, Cass CE, et al: Association of DNA repair and steroid metabolism gene polymorphisms with clinical late toxicity in patients treated with conformal radiotherapy for prostate cancer. Clin Cancer Res 12: 2545-2554, 2006.
20. Weischenfeldt J, Simon R, Feuerbach L, Schlangen K, Weichenhan D, Minner S, Wuttig D, Warnatz HJ, Stehr H, Rausch T, et al: Integrative genomic analyses reveal an androgen-driven somatic alteration landscape in early-onset prostate cancer. Cancer Cell 23: 159-170, 2013.

21. Barbieri CE, Baca SC, Lawrence MS, Demichelis F, Blattner M, Theurillat JP, White TA, Stojanov P, Van Allen E, Stransky N, et al: Exome sequencing identifies recurrent SPOP, FOXA1 and MED12 mutations in prostate cancer. Nat Genet 44: 685-689, 2012.

22. Erbersdobler A, Fritz H, Schnöger S, Graefen M, Hammerer P, Huland $\mathrm{H}$ and Henke RP: Tumour grade, proliferation, apoptosis, microvessel density, p53, and bcl-2 in prostate cancers: Differences between tumours located in the transition zone and in the peripheral zone. Eur Urol 41: 40-46, 2002.

23. Mirlacher M and Simon R: Recipient block TMA technique. Methods Mol Biol 664: 37-44, 2010.

24. Minner S, Enodien M, Sirma H, Luebke AM, Krohn A, Mayer PS, Simon R, Tennstedt P, Müller J, Scholz L, et al: ERG status is unrelated to PSA recurrence in radically operated prostate cancer in the absence of antihormonal therapy. Clin Cancer Res 17: 5878-5888, 2011.

25. Burkhardt L, Fuchs S, Krohn A, Masser S, Mader M, Kluth M, Bachmann F, Huland H, Steuber T, Graefen M, et al: CHD1 is a 5 q21 tumor suppressor required for ERG rearrangement in prostate cancer. Cancer Res 73: 2795-2805, 2013.

26. Kluth M, Hesse J, Heinl A, Krohn A, Steurer S, Sirma H, Simon R, Mayer PS, Schumacher U, Grupp K, et al: Genomic deletion of MAP3K7 at $6 \mathrm{q} 12-22$ is associated with early PSA recurrence in prostate cancer and absence of TMPRSS2:ERG fusions. Mod Pathol 26: 975-983, 2013.

27. Krohn A, Diedler T, Burkhardt L, Mayer PS, De Silva C, Meyer-Kornblum M, Kötschau D, Tennstedt P, Huang J, Gerhäuser C, et al: Genomic deletion of PTEN is associated with tumor progression and early PSA recurrence in ERG fusion-positive and fusion-negative prostate cancer. Am J Pathol 181: 401-412, 2012.

28. Krohn A, Seidel A, Burkhardt L, Bachmann F, Mader M, Grupp K, Eichenauer T, Becker A, Adam M, Graefen M, et al: Recurrent deletion of 3p13 targets multiple tumour suppressor genes and defines a distinct subgroup of aggressive ERG fusion-positive prostate cancers. J Pathol 231: 130-141, 2013.

29. Berger MF, Lawrence MS, Demichelis F, Drier Y, Cibulskis K, Sivachenko AY, Sboner A, Esgueva R, Pflueger D, Sougnez C, et al: The genomic complexity of primary human prostate cancer. Nature s470: 214-220, 2011.

30. Lapointe J, Li C, Giacomini CP, Salari K, Huang S, Wang P, Ferrari M, Hernandez-Boussard T, Brooks JD and Pollack JR: Genomic profiling reveals alternative genetic pathways of prostate tumorigenesis. Cancer Res 67: 8504-8510, 2007.

31. Taylor BS, Schultz N, Hieronymus H, Gopalan A, Xiao Y, Carver BS, Arora VK, Kaushik P, Cerami E, Reva B, et al: Integrative genomic profiling of human prostate cancer. Cancer Cell 18: 11-22, 2010.

32. Barnes DE, Stamp G, Rosewell I, Denzel A and Lindahl T: Targeted disruption of the gene encoding DNA ligase IV leads to lethality in embryonic mice. Curr Biol 8: 1395-1398, 1998.

33. Frank KM, Sekiguchi JM, Seidl KJ, Swat W, Rathbun GA, Cheng HL, Davidson L, Kangaloo L and Alt FW: Late embryonic lethality and impaired $V(D) J$ recombination in mice lacking DNA ligase IV. Nature 396: 173-177, 1998.

34. Gao Y, Sun Y, Frank KM, Dikkes P, Fujiwara Y, Seidl KJ, Sekiguchi JM, Rathbun GA, Swat W, Wang J, et al: A critical role for DNA end-joining proteins in both lymphogenesis and neurogenesis. Cell 95: 891-902, 1998.

35. Gatz SA, Ju L, Gruber R, Hoffmann E, Carr AM, Wang ZQ, Liu C and Jeggo PA: Requirement for DNA ligase IV during embryonic neuronal development. J Neurosci 31: 10088-10100, 2011.

36. Jeggo PA: Identification of genes involved in repair of DNA double-strand breaks in mammalian cells. Radiat Res 150 (Suppl 5): S80-S91, 1998

37. Tomlins SA, Rhodes DR, Perner S, Dhanasekaran SM, Mehra R, Sun XW, Varambally S, Cao X, Tchinda J, Kuefer R, et al: Recurrent fusion of TMPRSS2 and ETS transcription factor genes in prostate cancer. Science 310: 644-648, 2005.

38. Haffner MC, Aryee MJ, Toubaji A, Esopi DM, Albadine R, Gurel B, Isaacs WB, Bova GS, Liu W, Xu J, et al: Androgen-induced TOP2B-mediated double-strand breaks and prostate cancer gene rearrangements. Nat Genet 42: 668-675, 2010. 
39. Deweese JE and Osheroff N: Coordinating the two protomer active sites of human topoisomerase IIalpha: Nicks as topoisomerase II poisons. Biochemistry 48: 1439-1441, 2009.

40. Haffner MC, De Marzo AM, Meeker AK, Nelson WG and Yegnasubramanian S: Transcription-induced DNA double strand breaks: Both oncogenic force and potential therapeutic target? Clin Cancer Res 17: 3858-3864, 2011.

41. Tomkinson AE and Mackey ZB: Structure and function of mammalian DNA ligases. Mutat Res 407: 1-9, 1998.

42. Huang FC, Huang KF, Chen RH, Wu JE, Chen TC, Chen CL, Lee CC, Chen JY, Lin JJ and Huang HS: Synthesis, telomerase evaluation and anti-proliferative studies on various series of diaminoanthraquinone-linked aminoacyl residue derivatives. Arch Pharm (Weinheim) 345: 101-111, 2012.

43. Liu W, Lindberg J, Sui G, Luo J, Egevad L, Li T, Xie C, Wan M, Kim ST, Wang Z, et al: Identification of novel CHD1-associated collaborative alterations of genomic structure and functional assessment of CHD1 in prostate cancer. Oncogene 31: 3939-3948, 2012.

44. Varga T and Aplan PD: Chromosomal aberrations induced by double strand DNA breaks. DNA Repair (Amst) 4: 1038-1046, 2005.

45. Schlade-Bartusiak K, Tucker T, Safavi H, Livingston J, van Allen MI, Eydoux $\mathrm{P}$ and Armstrong L: Independent post-zygotic breaks of a dicentric chromosome result in mosaicism for an inverted duplication deletion $9 \mathrm{p}$ and terminal deletion 9p. Eur J Med Genet 56: 229-235, 2013.
46. Carter SL, Eklund AC, Kohane IS, Harris LN and Szallasi Z: A signature of chromosomal instability inferred from gene expression profiles predicts clinical outcome in multiple human cancers. Nat Genet 38: 1043-1048, 2006.

47. Walther A, Houlston R and Tomlinson I: Association between chromosomal instability and prognosis in colorectal cancer: A meta-analysis. Gut 57: 941-950, 2008.

48. Schlomm T, Iwers L, Kirstein P, Jessen B, Köllermann J, Minner S, Passow-Drolet A, Mirlacher M, Milde-Langosch K, Graefen M, et al: Clinical significance of p53 alterations in surgically treated prostate cancers. Mod Pathol 21: 1371-1378, 2008.

49. Bubendorf L, Sauter G, Moch H, Schmid HP, Gasser TC, Jordan P and Mihatsch MJ: Ki67 labelling index: An independent predictor of progression in prostate cancer treated by radical prostatectomy. J Pathol 178: 437-441, 1996.

50. El Gammal AT, Brüchmann M,Zustin J, Isbarn H, Hellwinkel OJ, Köllermann J, Sauter G, Simon R, Wilczak W, Schwarz J, et al: Chromosome $8 \mathrm{p}$ deletions and $8 \mathrm{q}$ gains are associated with tumor progression and poor prognosis in prostate cancer. Clin Cancer Res 16: 56-64, 2010.

51. Grupp K, Kohl S, Sirma H, Simon R, Steurer S, Becker A, Adam M, Izbicki J, Sauter G, Minner S, et al: Cysteine-rich secretory protein 3 overexpression is linked to a subset of PTEN-deleted ERG fusion-positive prostate cancers with early biochemical recurrence. Mod Pathol 26: 733-742, 2013. 